\title{
Learning histology - dental and medical students' study strategies
}

\author{
S. Johnson ${ }^{1}$, J. Purkiss ${ }^{2}$, L. Holaday ${ }^{2}$, D. Selvig ${ }^{2}$ and M. Hortsch ${ }^{2}$ \\ ${ }^{1}$ School of Dentistry, University of Michigan, Ann Arbor, MI, USA, \\ ${ }^{2}$ Medical School, University of Michigan, Ann Arbor, MI, USA
}

\author{
keywords \\ histology; dental education; medical education; \\ educational technology; e-learning. \\ Correspondence \\ Michael Hortsch \\ Departments of Cell and Dev. Biology and of \\ Medical Education, \\ University of Michigan, \\ 1137 E. Catherine St., 3761B Med. Sci. II Bldg., \\ Ann Arbor, Ml 48109, USA \\ Tel: +17346472720 \\ Fax: +1 7346158191 \\ e-mail: hortsch@umich.edu
}

Accepted: 18 March 2014

doi: 10.1111/eje.12104

\begin{abstract}
Purpose: Histology, the science of cells and tissues at the microscopic level, is an integral component of most dental and medical curricula and is often taught using both traditional and novel computer-based didactic approaches. The purpose of this study was to analyse the strategies used by dental and medical students when studying this very visual and challenging subject.
\end{abstract}

Methods: Data were collected from 75 dental and 143 medical students, who had almost identical histology learning resources at their disposal.

Results: When compared with their medical counterparts, dental students view histology as a more difficult subject and as less relevant for their future career. Whereas dental students, who are required to attend class unlike medical students, made more use of in-classroom learning opportunities, they did not take as much advantage of out-ofclassroom resources. In addition, dental students reported a significantly higher tendency than medical students to work together, rather than to study alone.

Discussion: Small differences in the dental versus the medical learning environment associate with several observed differences in learning strategies that are adopted by dental and medical students.

Conclusions: These differences should be considered when teaching the subject of histology to dental or to medical students.

\section{Introduction}

Over the last 20 years, many novel electronic teaching tools and approaches have complemented and, in many cases, supplanted traditional educational offerings, such as lectures, textbooks and laboratory sessions (1-4). This general trend has also resulted in many changes in how we educate students at the professional school level, including dental and medical programs. Histology, a traditional component of both dental and medical curricula, is a subject that has experienced many such changes $(5,6)$. As histology sits at the crossroads of the macroscopic and molecular medical sciences and serves as a bridge connecting gross anatomy, biochemistry, pathology and physiology amongst other subjects, it initially appears daunting to many students, especially those who had no previous histology experience. Histology is usually taught at the beginning of dental and medical courses of study. An increasing number of dental and medical schools teach this very visual subject using modern technologies, such as recorded lecture videos, virtual microscopy, online instruction and Internet-based learning modules (7-9). A number of reports indicate that novel instructional approaches are usually embraced by today's student population and sometimes result in improved learning outcomes (10-15).

We recently analysed the choices made by medical students at the University of Michigan in selecting between different resources and adapting specific learning strategies during their M1 histology component (16). Medical students were found to 
exhibit a strong tendency to abandon scheduled histology learning opportunities (lectures and laboratory sessions) as the semester went on and to increase their use of many electronic resources that can be accessed without time restrictions (lecture videos, an Internet-based virtual microscopy collection and other computer-based learning modules). Medical students also tend to study histology alone, rather than with other classmates. Resources that are interactive and give efficient feedback are especially popular.

These findings raised the question of whether dental students approach histology in the same way. The project described in this paper investigated the choices made by dental students for learning histology and compares them with their medical student counterparts. As there are small differences between the dental and medical curricula, the respective learning environments and the students themselves, we expected to find some differences in how dental and medical students approach histology, adopt specific learning strategies and select specific didactic resources. These insights might help to create optimised learning conditions for teaching histology to both dental and medical students.

\section{Methods}

\section{Structure of dental and medical histology components}

The University of Michigan Dental and Medical School curricula are designed to complete the academic work for a D.D.S. and an M.D. degree, respectively, within a 4-year time period. The dental curriculum involves organ-system-based courses, which are taught year-round for the first 2 years of dental school. Histology is incorporated in six of these courses. Before the systems-based courses, dental students participate in a basic science summer course teaching the fundamentals of histology. The lectures for the histology portion of all courses consist of traditional PowerPoint lectures followed by a second PowerPoint presentation that focuses on a more image-based introduction to the virtual slides that are offered on the Dental Histology course website (http://histology.med.umich.edu/dental). Dental students do not have the option to examine histological glass slides using real microscopes but are encouraged to work with the virtual slides on their own time. The dental histology component has $32 \mathrm{~h}$ of direct contact hours of instructions, either lecture or laboratory introduction. Students are officially required to attend all lectures. However, attendance is not documented or enforced for histology lectures. Video recordings of the lectures are also available to all dental students. Learning success and competency in histology for the introductory dental histology course is assessed by a final, pass-fail 50 multiple-choice question online examination. For all organ-system-based courses four to five image-based multiple-choice questions per histology lecture hour are included in the course's midterm or final examination. Only the first basic dental histology course is offered on a pass/fail basis. All later organ-based dental courses with a histology component are graded on a 4.0 scale. Oral histology and pathology for dental students are taught in separate courses and are not part of this analysis.
The M1 year (first year of medical school) is organised into multiweek, organ-system-based sequences and histology is taught in eight of these sequences. The M1 histology component offers $26 \mathrm{~h}$ of lectures and 21 three-hour laboratory sessions in total. Most of the teaching faculty and the lecture content are identical for dental and medical histology instruction. However, the medical curriculum contains several topics that are not taught at the dental school, specifically, ear, eye, endocrine, male reproductive and integumentary system histology. Attendance of histology lectures and laboratory sessions at the medical school is voluntary. Alternatively, students have the choice to view histology lectures online and to perform laboratory assignments on their own time. Each laboratory session begins with a PowerPoint introduction to the virtual slide material (approximately $30 \mathrm{~min}$ ) that is presented by a faculty member and is equivalent to the laboratory introduction offered to dental students. Subsequently, students have the opportunity to work on their laboratory assignments in the presence of histology teaching faculty members. During the laboratory sessions, M1 students have some additional learning resources available to them that are not offered to dental students. These include a set of real microscopes for the viewing of histological glass slides and poster-size, labelled electron micrographs that are displayed in the hallways outside the laboratory rooms. Only a very small number of medical students make use of the opportunity to look at glass slides with real microscopes (16). Similar to the dental histology component, PowerPoint files of the lectures and laboratory introductions and supplemental learning resources can be downloaded by students from the Medical Histology course website. At the medical school, learning success in histology is evaluated by multiple-choice questions with associated images during weekly online quizzes and a final online examination for each organsystem-based unit. In contrast to the School of Dentistry, these organ-based courses are on a pass/fail basis.

The purchase of a histology textbook or atlas is strongly recommended to all students at the beginning of their D1/M1 histology component. All of the electronic histology learning tools are available to students and faculty at the Medical and Dental Histology course websites (http://histology.med.umich.edu/ schedule/medical and http://histology.med.umich.edu/schedule/ dental). Although in a different order, these websites contain largely the same material. They allow the downloading of the same histology resources (lecture handouts and various series of PowerPoint and PDF files) and contain the same learning objectives, laboratory instructions and links to the Michigan virtual slide collection. The end of each organ-based web section contains a number of digital electron micrographs (identical to the posters available to medical students) and sample multiple-choice questions. The supplemental PowerPoint and PDF file series include whiteboard histological drawings, which summarise histology terminology and structures; summary sheets (in PDF format), which summarise the most salient points of each study subject in table form; labelled still shots of virtual histology micrographs as PowerPoint files; 'Review and Look-Alike' PowerPoint files that specifically address similarlooking histological structures and tissues; and the 'SecondLook' PowerPoint series that provides students with a self-evaluation tool to test their preparedness before quizzes and examinations 
and is also available as a computer tablet application (http:// www.med.umich.edu/lrc/secondlook/).

\section{Structure of online surveys}

This project received an exemption from the University of Michigan Institutional Medical Review Board (IRBMED application numbers HUM00048823 and HUM00076634). The results presented in this paper are derived from two online surveys that were administered to the University of Michigan Dental School and Medical School Classes of 2015 following the completion of their respective histology modules. The survey items were initially drafted by the histology component director (M.H.) whose experience in histology education and knowledge regarding the various resources and study patterns common to students at the University of Michigan, promoted content validity. The survey then underwent a careful review and editing process. The involvement of a dental (S.J.) and of two medical students (D.S. and L.W.H.), who provided significant input as peers of the target audience, was key to this process. Further, a faculty member with expertise and significant experience in survey research methodology (J.P.) also contributed to the review and editing process. Seventy-five of 106 or $70.8 \%$ of dental students and 143 of 167 or $85.6 \%$ of medical students participated and answered the survey questions. The surveys were constructed using the Qualtrics online survey service (http://www. qualtrics.com) and consisted of 19 question-sets for dental and 20 question-sets for medical students, most of which were identical in both surveys, specifically those used in the analysis presented here. For each resource, students were asked to describe on a five-level Likert scale ('Always', 'Frequently', 'Moderately', 'Rarely', or 'Never'; scored from 5 to 1) how often they used each resource and whether their use of that resource increased, decreased or remained the same over the course of their histology component. A few questions allowed participating students to enter text-based, open-ended responses. Demographic characteristics and past educational experiences, like college major, time since graduation and previous relevant coursework or research experience were also assessed. Additional questions focused on histology study habits, specifically individual versus group study. Not all participating students answered all questions. The respective surveys were open for about 1 month and non-responding students received weekly reminder emails. Participation in both surveys was entirely voluntary, but was encouraged by the random drawing of $\$ 70$ cash prizes (approximately one for every 30 participating students). Prior to data analysis, all survey responses were rendered anonymous by a study contributor who was not involved in teaching histology.

\section{Statistical analysis and other materials}

IBM SPSS Statistics Version 19 was used for the statistical analysis. We calculated descriptive statistics including percentages, means and standard deviations to summarise student response patterns for the various survey items. We used two-tailed $t$-tests and a threshold of $P=0.05$ for assessing statistical significance. A commercial use license for the icons used in Fig. 4 was purchased from psdGraphics, Columbus, Ohio.

\section{Results}

\section{Students' assessment of histology as part of their professional education}

To assess the overall motivation of dental and medical students to study and to learn histology, students were asked how relevant they believe histology is for their future career as a dentist or physician. The average score on a five-level Likert scale ranging from 'Not relevant at all' (score of 1) to 'Very relevant' (score of 5) was 2.89 for dental students and 3.31 for medical students (Fig. 1). This difference in viewing histology as relevant and therefore important for the dental or medical profession is highly significant $(P=0.001)$.

After completing the histology component of their respective curriculum, both groups of students were asked how difficult they envisioned histology as a study subject before starting histology lessons and after histology lessons were completed. Both groups viewed histology as a difficult study subject before the start of their histology component. On a five-level Likert scale from 'Very Difficult' (score of 1) to 'Very easy' (score of 5) the average difficulty score for histology reported by the dental students was 1.97 vs. 2.72 for the medical school class (Fig. 2). This difference of dental students judging histology as a more difficult subject than medical students is highly significant $(P<0.001)$. After completion of the histology component, both groups of students viewed the degree of difficulty for histology as medium, with an average score for the dental class of

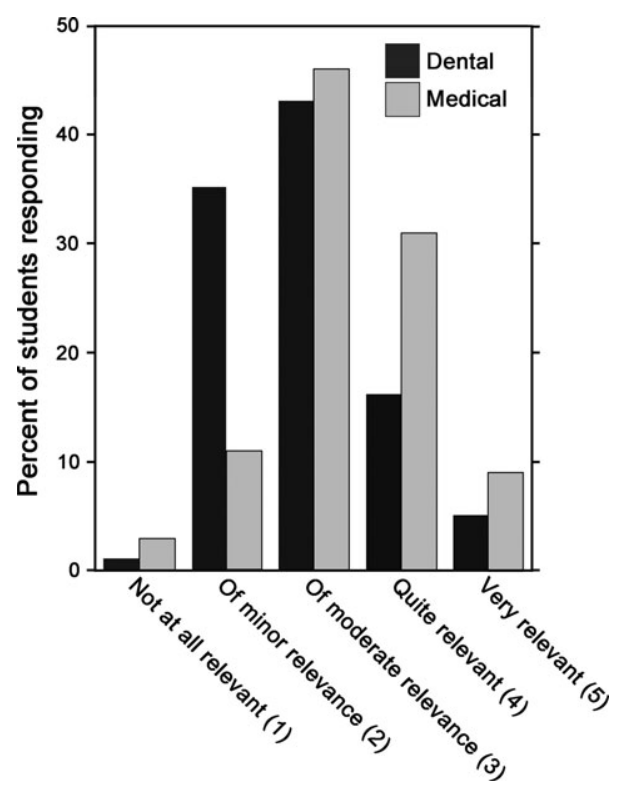

Fig. 1. Perceived importance of histology for a career as dentist or physician. The bar graph depicts students' answers to the question 'How important do you think histology is for a future career in dentistryl medicine?' Students were able to choose from a five-point Likert scale ranging from 'Not at all relevant' (score of 1) to 'Very relevant' (score of 5). The difference between the average for the dental class $(2.89 \pm 0.88)$ and the medical class $(3.31 \pm 0.89)$ is highly significant $(\mathrm{P}$-value $=0.001)$. 


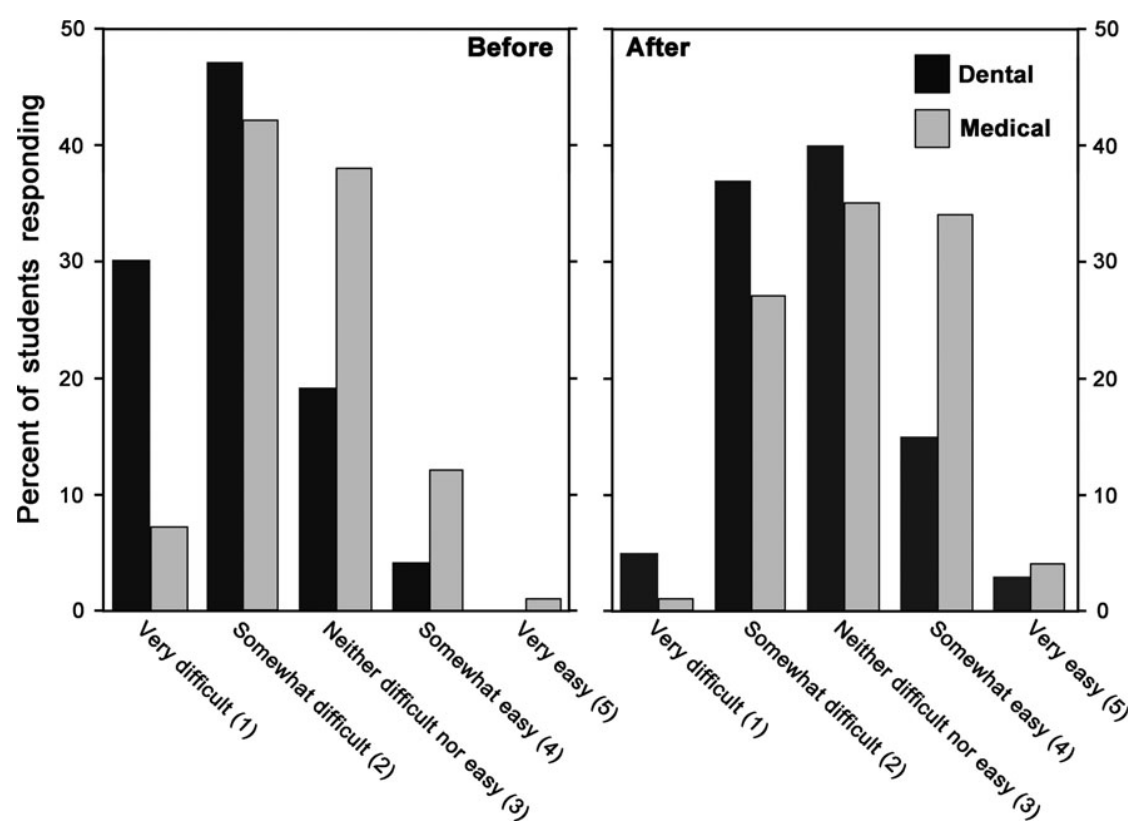

Fig. 2. Students' view of histology as a difficult/easy learning subject BEFORE and AFTER completion of the dental /medical histology component. This bar graph shows students' views of histology as an easy/difficult study subject. Students were able to choose their answers from a five-point Likert scale ranging from 'Very difficult' (score of 1) to 'Very easy' (score of 5). Black bars depict dental students' answers and the grey bars those of medical students. The left part of the figure shows students' attitudes as they remembered BEFORE they started their histology learning experience and the right bar graph AFTER their respective histology component was finished. The differences between the answers for BEFORE versus AFTER the histology component are highly significant for both classes (Dental class $1.97 \pm 0.81$ and $2.72 \pm 0.88$ with a P-value $<0.001 ;$ medical class $2.57 \pm 0.82$ and $3.12 \pm 0.88$ with a P-value<0.001). Equally, the averages between the dental and the medical class for both BEFORE and AFTER are also highly significant (BEFORE: $1.97 \pm 0.81$ vs. $2.57 \pm 0.82$ with a P-value $=0.001 ;$ AFTER: $2.72 \pm 0.88$ vs. $3.12 \pm 0.88$ with a P-value $=0.002$ ).

2.57 and for the medical class of 3.12 (Fig. 2). Again, this shift of viewing histology as an easier subject than before instruction had started is highly significant, with $P$-values of $<0.001$ for dental and 0.002 for medical students. The difference in the difficulty score between the dental and the medical class decreased from 0.75 to 0.55 , however, this difference remained highly significant $(P<0.001)$ (Fig. 2$)$. Interestingly, the dental class has a much higher percentage of students who reported that they had been exposed to histology/pathology during their previous education or work in a research laboratory (51 of 75 or $68 \%$ for the dental class vs. 49 of 142 or $35 \%$ for the medical class).

\section{Students' study habits}

A previous analysis of the histology study strategies adopted by medical students found that most students choose to study alone rather than together with classmates (16). Figure 3 shows the answers to the same question given by corresponding medical and dental classes. The answers given by this medical school class (Class of 2015) are very similar to those published earlier (Class of 2014) (16). Although a majority of dental students also reported that they 'Always' (score of 5) or 'Frequently' (score of 4) study histology alone and this study modus also showed an increase over the progression of the dental histology component, many more medical students reported that they learned histology alone (a 4.11 vs. a 4.64 class average score with a highly significant $P$-value of $<0.001)$. When the question was asked in reverse 'How frequently did you study histology with others?', the responses from both classes again indicated that dental students are significantly more likely to learn histology in a study group when compared with medical students (a 2.43 vs. a 2.01 class average with a $P$-value of 0.007 ). It should be noted that these numbers reflect the self-reported views of students' own study habits. Not all students who reported that they 'Always' study histology alone also reported that they 'Never' study with others and vice versa.

\section{Students' use of histology learning resources}

Dental and medical students at the University of Michigan have access to substantially similar sets of histology learning resources. Traditional delivery methods, such as lectures and textbooks, are complemented by modern electronic media, which include lecture videos, course websites with virtual microscope images and various sets of supplemental PowerPoint and PDF files. The overall pattern of learning resource selection by dental and medical students is very similar (Table 1) with many electronic learning tools being very popular and exhibiting an increase in usage over time (Fig. 4). However, there are a number of highly significant differences between dental and medical students in their usage of specific learning resources. As expected, as lecture attendance is mandated at the dental school and is voluntary at the medical school, dental students reported 


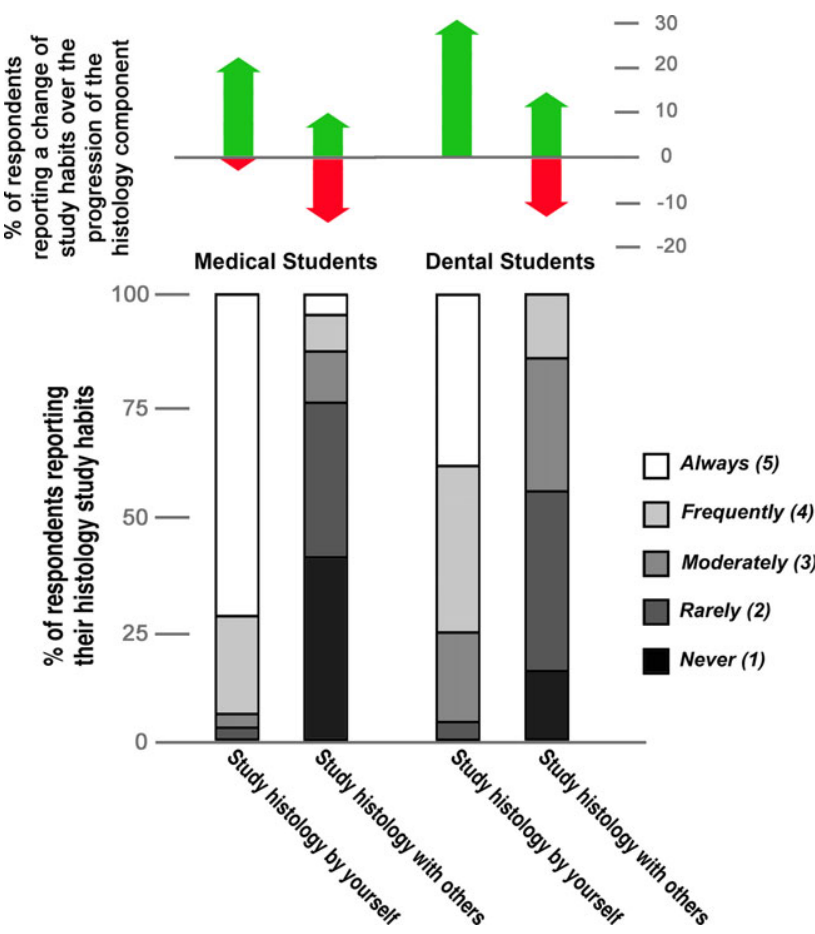

Fig. 3. Reported modus of studying histology either alone or in a study group. The figure depicts the answers of medical and dental students to the question 'How frequently (on average) did you use the following study habits (study by yourself or study with others) for learning histology?' Students' answers reflect their choice from a five-point Likert scale ranging from 'Always' (score of 5) to 'Never' (score of 1). The top panel reflects students' answers to the follow-up question whether this mode of study increased, stayed the same or decreased over time. The differences of the average answers to both questions are highly significant between the dental and medical class (For 'working alone' P-value $<0.001$ and for 'working in a study group' P-value $=0.007$ ).

a significantly higher attendance of lectures and laboratory introduction presentations than medical students (Table 1). The previously reported tendency of medical students to abandon scheduled didactic learning opportunities (lectures, laboratory introductions and laboratory sessions) (16) was not observed for dental students (Fig. 4). In contrast, dental students reported that they increased their usage of most histology resources as time progressed.

However, dental students reported less use of the histology course website to study virtual microscopy images on their own time $(P=0.0004)$ (Table 1$)$. When compared with medical students' responses, they also used the examination sample questions at the end of each subject webpage significantly less often $(P=0.0001)$. The least popular learning resource for both student populations was a histology textbook/atlas. It was the only learning resource that dental students reported using less over time (Fig. 4).

\section{Discussion}

As dental and medical students at the University of Michigan receive their training in histology by the same teaching staff and are offered very similar arrays of learning resources, we wondered whether the small differences in the learning environment and in the academic curriculum would correlate with different choices by dental versus medical students when selecting learning resources and adopting specific learning strategies. Very few studies have used a comparison between dental and medical students for revealing similarities or differences in their attitudes, learning strategies and preferences of resource usage $(15,17)$. Snelling et al. reported that dental and medical students equally value many of the same educational resources offered to them in a gross anatomy course (17). However, they also found a few differences between dental and medical students in their attitude to gross anatomy teaching. Looking at the use of light microscopy versus digital media by dental and medical students for learning histology, Schmidt recently reported that both groups of students prefer electronic learning resources (15).

We initially asked whether dental students differ from their medical counterparts in their motivation to learn histology as part of their basic biomedical science education. As a measure for their motivation, both dental and medical students were asked how relevant they felt histology to be for their professional career as future dentists or physicians. Medical students reported histology to be significantly more relevant to their future career than dental students (Fig. 1). This observation agrees with a decreasing emphasis on teaching histology to today's dental students at many North American dental schools (18) and therefore might reflect a more general view that histology is not of central importance for a practicing dentist.

In addition, the lower emphasis dental students place on histology may also influence students' view of histology as a difficult or easy subject to learn. Both medical and dental students reported that they believed histology to be a difficult subject (Fig. 2), with dental students reporting a significantly greater initial expectation of difficulty. However, a greater proportion of dental students reported a previous experience with histology or pathology ( 51 of 75 , or $68 \%$ of dental students vs. 49 of 142 , or $35 \%$ of medical students), which makes this finding even more impressive. As might be expected, both groups of students find histology significantly less challenging after the completion of their respective histology education. Another aspect that might have an impact could be a difference in the academic preparedness between dental and medical students. Indeed, the average undergraduate GPA of the medical school class of 2015 is $3.78 \pm 0.18$, which is significantly higher than that of the dental school class of 2015, which is $3.51 \pm 0.29$ (Independent-samples $t$-test: $P$-value $<0.001$ and $t$-value $=9.51$ ). As Forester et al. (19) reported a direct beneficial relationship between premedical coursework in gross anatomy and histology and students' performance in medical school, the greater previous exposure to histology might counteract the effect of the lower GPA average score of the dental class. It would be interesting to find out how these factors influence test and examination results in histology by dental and medical students. However, the differences in the order and the way examinations are administered at the dental versus the medical school make such a comparison less meaningful.

A majority of both dental and medical students reported that they 'Always' or 'Frequently' study alone rather than with a 
TABLE 1. Quantitative comparison of the overall usage frequencies by dental versus medical students for specific histology learning resources. This table provides descriptive statistics (means of overall resource usage and standard deviations) summarising student responses to the survey items regarding overall frequency of use for 12 specific histology study resources (13 items for medical students as a faculty-guided laboratory session was not offered to dental students). The means in column 2 and 4 represent students' overall reported usage of this resources as encoded by $1=$ Never; $2=R a r e l y$; $3=$ Moderately; $4=$ Frequently and $5=$ Always. Higher means indicate greater reported use of this resource by all survey respondents $(\mathrm{N}$ in columns 3 and 5). As not all survey participants provided an answer, $\mathrm{N}$ varies for the reported usage of a specific study resource. Column 6 shows the difference of the class average mean between the dental and the medical class. Columns 7 and 8 contain the statistical analysis for the usage differences between the dental and medical class, t-values and P-values

\begin{tabular}{|c|c|c|c|c|c|c|c|c|}
\hline & & $\begin{array}{l}\text { Dental class of } \\
2015\end{array}$ & & $\begin{array}{l}\text { Medical class } \\
2015\end{array}$ & & & & \\
\hline & Frequency of resource usage ( $1=$ never to $5=$ always $)$ & Mean & $N$ & Mean & $N$ & Mean difference & $t$-values & $P$-values \\
\hline 1 & Attending the lectures in person & $4.27 \pm 0.96$ & 75 & $3.88 \pm 1.19$ & 142 & 0.39 & 2.45 & $0.0152 *$ \\
\hline 2 & Viewing of lecture videos & $3.43 \pm 1.05$ & 75 & $2.87 \pm 1.41$ & 142 & 0.56 & 3.02 & $0.0028 * *$ \\
\hline 3 & Attending laboratory introductions in person & $4.09 \pm 1.07$ & 74 & $3.25 \pm 1.44$ & 142 & 0.84 & 4.42 & $0.0001 * *$ \\
\hline 4 & $\begin{array}{l}\text { Studying the laboratory introduction } \\
\text { PowerPoint files independently }\end{array}$ & $4.18 \pm 1.01$ & 74 & $3.73 \pm 1.37$ & 142 & 0.45 & 2.49 & $0.0134 *$ \\
\hline 5 & $\begin{array}{l}\text { Attending laboratory sessions with faculty } \\
\text { help in person }\end{array}$ & - & - & $2.46 \pm 1.37$ & 142 & - & - & - \\
\hline 6 & $\begin{array}{l}\text { Work on laboratory assignments on own time } \\
\text { (course webpage with virtual microscope images) }\end{array}$ & $2.97 \pm 1.16$ & 75 & $3.63 \pm 1.36$ & 142 & -0.66 & 3.57 & $0.0004 * *$ \\
\hline 7 & Use of Whiteboard Drawing PowerPoint files & $2.79 \pm 1.29$ & 75 & $2.69 \pm 1.54$ & 142 & 0.10 & 0.48 & 0.6316 \\
\hline 8 & Use of Summary Sheet PDF files & $3.39 \pm 1.29$ & 75 & $3.20 \pm 1.44$ & 142 & 0.19 & 0.96 & 0.3394 \\
\hline 9 & Use of Labelled Micrograph PowerPoint files & $3.09 \pm 1.32$ & 75 & $2.52 \pm 1.52$ & 141 & 0.57 & 2.74 & $0.0066 * *$ \\
\hline 10 & Use of Review and Look-Alikes PowerPoint files & $4.01 \pm 1.22$ & 75 & $3.92 \pm 1.28$ & 142 & 0.09 & 0.50 & 0.6172 \\
\hline 11 & Use of SecondLook Self-Evaluation PowerPoint files & $4.77 \pm 0.45$ & 74 & $4.94 \pm 0.31$ & 142 & -0.17 & 3.26 & $0.0013 * *$ \\
\hline 12 & Use of practice questions in online course website & $3.36 \pm 1.28$ & 75 & $4.18 \pm 1.08$ & 142 & -0.82 & 4.98 & $0.0001 * *$ \\
\hline 13 & Use of a histology textbook & $1.81 \pm 0.98$ & 75 & $1.37 \pm 0.81$ & 142 & 0.44 & 3.53 & $0.0005^{* *}$ \\
\hline
\end{tabular}

*Statistically significant $P<0.05$.

**Statistically highly significant $P<0.01$.

group of peers and that this study modus is more prevalent over time (Fig. 3) (16). As it is documented by a number of different studies, group learning in science courses using advanced technology usually improves students' performance when compared with individual learning $(20,21)$. Therefore, the strong preference of dental and medical students to learn histology alone might be counteractive to their learning success. Interestingly, significantly more dental than medical students report that they participate in study groups for acquiring histology knowledge and skills. One reason for the more cooperative spirit amongst dental students may be rooted in the fact that due to the compulsory lecture and laboratory attendance policy at the dental school, they are spending considerably more time together. The smaller size of the Michigan dental class (about 110 students) versus the medical class (about 170 students) might be another contributing factor for favouring a more collaborative atmosphere. It has been reported that larger class sizes reduce students' involvement in the learning process and lower academic achievement (22).

Despite some quantitative differences, the overall use pattern for specific histology learning resources by dental students is very similar to that previously reported for medical students (16). In particular, electronic learning resources that give fast and efficient feedback are extremely popular with both groups of students (Fig. 4 and Table 1). The least popular learning resource for both dental and medical students is a traditional textbook or histology atlas. When asked for the title of the textbook/atlas used during their histology learning process, only $25.3 \%$ of dental students and $22.5 \%$ of medical students named a specific title. This result supports similar findings in a recent study by Ditmyer et al. (23), who found that more than $75 \%$ of surveyed dental students 'spent little time studying from their textbooks.'

Despite these similarities between the survey answers given by dental and medical students, there are several significant differences. As previously reported, medical students abandoned educational offerings that have a fixed time schedule, notably, lectures and laboratory sessions, as the academic year progressed (16). In contrast, more dental students reported an increase rather than a decrease in the use of lectures and laboratory introduction sessions. There is a significant quantitative difference between dental and medical students in their self-reported attendance of lecture and laboratory introduction sessions (Table 1, Rows 1 and 3). These differences are most likely a result of the different attendance policies at the dental and the medical school, respectively. All Michigan dental students are expected to be present at all scheduled lectures and laboratory sessions. In contrast, most educational events of the first year Michigan medical curriculum have no attendance requirement. Both classes have access to video recordings of all lectures, and, interestingly, dental students reported greater use of these recordings despite their higher classroom attendance. It has been argued that compulsory class attendance might have a detrimental effect on students in a higher education learning environment (24). However, this does 

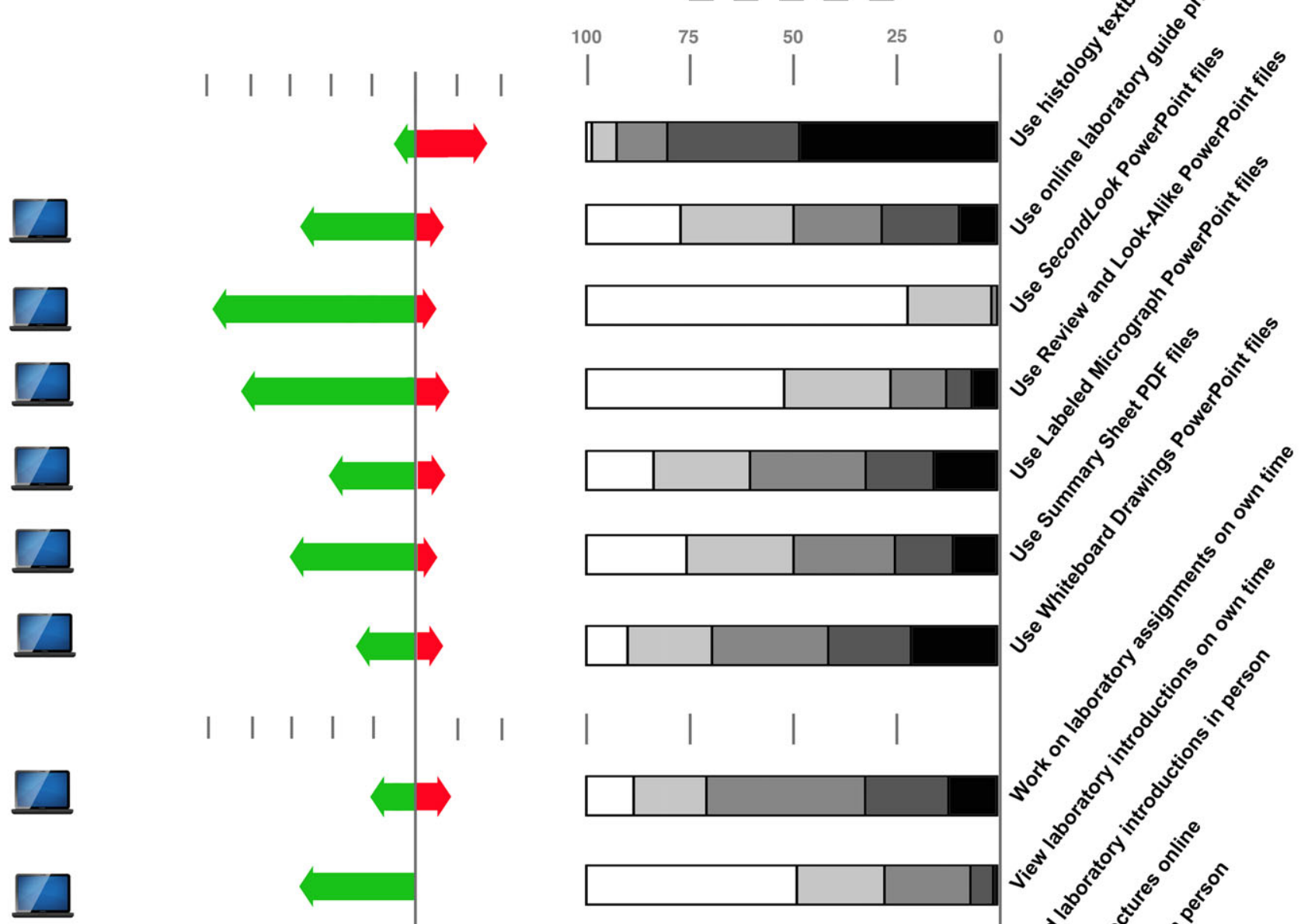

(10)
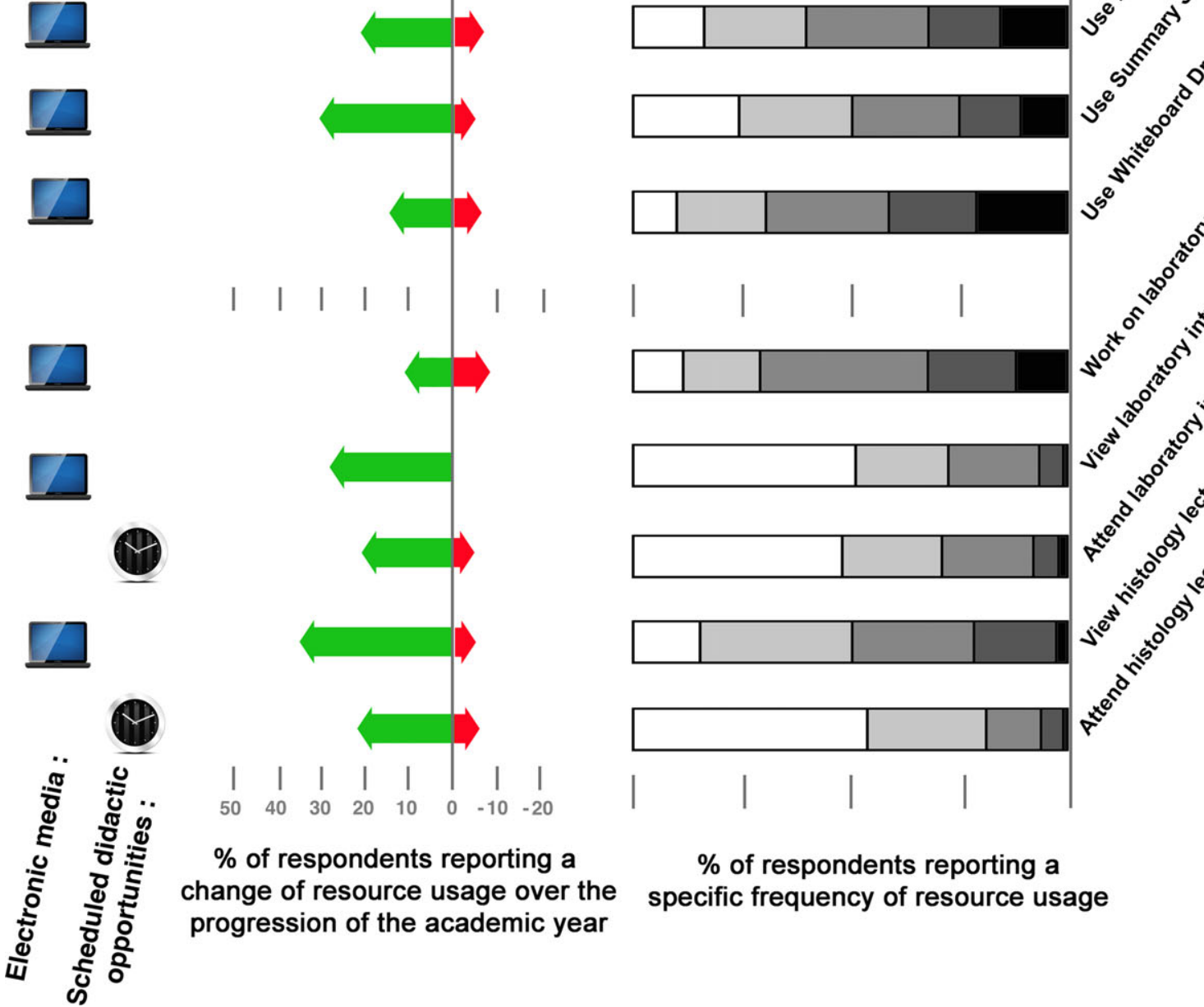

$\%$ of respondents reporting a change of resource usage over the progression of the academic year

$\%$ of respondents reporting a specific frequency of resource usage

Fig. 4. Overall usage of different histology study resources and reported changes over the progression of the dental histology component. The monitor icon on the left indicates electronic histology study tools, such as lecture videos or downloadable PowerPoint files, and the clock icon marks educational offerings that are restricted to specific times, such as lectures and laboratory introduction sessions. The right panel depicts the reported overall usage frequency of specific educational resources as selected on a five-point Likert scale from 'Always' (score of 5) to 'Never' (score of 1). The arrows in the middle panel specify the percentages of students, who reported an increase or a decrease of the use of this resource over the progression of the dental histology component. $\mathrm{N}=75$. 
not appear to be the case for the majority of dental students. When asked to list the three most valuable histology learning resources, $55 \%$ of dental students named 'attend lectures in person', compared with only $35 \%$ of medical students. Thus, it is possible that there are dental students who would otherwise choose not to attend lectures in person, but in fact derive great value from the requirement to do so. With the increasing availability of lecture videos, it is a matter of intense discussion whether lecture attendance is an important factor in higher education (25). However, there is good evidence in the literature that lecture attendance has a significant positive impact on students' academic performance $(26,27)$.

One unexpected finding of the survey was that dental students made little use of the Dental Histology course website (http:// histology.med.umich.edu/schedule/dental) (Table 1, Row 6). This finding is especially surprising as multiple studies report that students embrace Internet or web-based instruction at the dental and the medical school level $(7,8,28-31)$. The underutilisation of the dental histology course webpage may be an unintended consequence of the school's required attendance policy which might raise an expectation by the students that most learning takes place in the classroom or the laboratory. Furthermore, as dental students are required to attend lectures and have extensive laboratory assignments, they have less free time during which to peruse the website. Informal discussions with many dental students lend some support to the former assumption.

As this study only analyses one dental and one medical class, one might question whether these two classes represent general student attitudes. However, in our longitudinal comparison of three different medical school classes, little year-to-year variation between students' responses was observed, and we are therefore confident that the data presented in this manuscript are reasonably characteristic (32). One limitation of this study is its reliance on subjective student answers for some of the questions using a Likert scale. As a result, the numbers are more representative of trends rather than exact quantitative measurements of actual students' behaviour. However, the data presented here agree well with casual observations (e.g. lecture attendance) and with many informal conversations with individual students.

This analysis is based on the educational environment and the situation at the University of Michigan. Although the curriculum, the range of instructional material and the characteristics of the student population may differ at other educational institutions, many of the specific elements are likely to be similar. Therefore, this analysis should be helpful for improving teaching strategies for histology at a broader scale, for developing more effective didactic resources, and for better serving dental and medical students.

\section{Conclusion}

This comparison of attitudes, study strategies and usage of different learning resources by dental and medical students for learning histology during their basic science education yields some interesting insights into how different populations of students make choices about their study habits and how small differences in curricular policy may influence these choices. Dental students think of histology as less relevant for their professional career than medical students, and they also view histology as a considerably more challenging subject. This suggests that different approaches might be needed to successfully integrate histology into a dental versus a medical school curriculum. When looking at the choices students are making between traditional and modern electronic resources, it becomes clear that both groups of students gravitate towards electronic tools, especially those that give quick and efficient feedback. Although the compulsory attendance policy at the Michigan School of Dentistry correlated with more students attending scheduled didactic events, it might influence students' motivation to use out-of-classroom learning opportunities. Therefore, the benefits of such policies need to be carefully balanced with their potential disadvantages.

\section{References}

1 Schittek M, Mattheos N, Lyon HC, Attstrom R. Computer assisted learning. A review. Eur J Dent Educ 2001: 5: 93-100.

2 Mattheos N, Stefanovic N, Apse P, et al. Potential of information technology in dental education. Eur J Dent Educ 2008: 12 (Suppl. 1): 85-92.

3 Ruiz JG, Mintzer MJ, Leipzig RM. The impact of e-learning in medical education. Acad Med 2006: 81: 207-212.

4 Ogilvie RW, Trusk TC, Blue AV. Students' attitudes towards computer testing in a basic science course. Med Educ 1999: 33: 828-831.

5 Hortsch M. Virtual biology: teaching histology in the age of facebook. FASEB J 2013: 27: 411-413.

6 Bloodgood RA, Ogilvie RW. Trends in histology laboratory teaching in United States medical schools. Anat Rec B New Anat 2006: 289: 169-175.

7 Cotter JR. Laboratory instruction in histology at the university at buffalo: recent replacement of microscope exercises with computer applications. Anat Rec 2001: 265: 212-221.

8 Rosas C, Rubi R, Donoso M, Uribe S. Dental students' evaluations of an interactive histology software. J Dent Educ 2012: 76: 1491-1496.

9 MacPherson BR, Brueckner JK. Enhancing the dental histology curriculum using computer technology. J Dent Educ 2003: 67: 359-365.

10 Farah CS, Maybury TS. The e-evolution of microscopy in dental education. J Dent Educ 2009: 73: 942-949.

11 Gadbury-Amyot CC, Singh AH, Overman PR. Teaching with technology: learning outcomes for a combined dental and dental hygiene online hybrid oral histology course. J Dent Educ 2013: 77: 732-743.

12 Lei LW, Winn W, Scott C, Farr A. Evaluation of computer-assisted instruction in histology: effect of interaction on learning outcome. Anat Rec B New Anat 2005: 284: 28-34.

13 Dickerson J, Kubasko D. Digital microscopes: enhancing collaboration and engagement in science classrooms with information technologies. Contemp Issues Technol Teach Educ 2007: 7: 279-292.

14 Triola MM, Holloway WJ. Enhanced virtual microscopy for collaborative education. BMC Med Educ 2011: 11: 4.

15 Schmidt P. Digital learning programs - competition for the classical microscope? GMS Z Med Ausbild 2013: 30: Doc8.

16 Holaday L, Selvig D, Purkiss J, Hortsch M. Preference of interactive electronic versus traditional learning resources by University of Michigan medical students during the first year histology component. Med Sci Educ 2013: 23: 607-619.

17 Snelling J, Sahai A, Ellis H. Attitudes of medical and dental students to dissection. Clin Anat 2003: 16: 165-172. 
18 Burk DT, Lee LM, Lambert HW. Embryology and histology education in North American dental schools: the basic science survey series. J Dent Educ 2013: 77: 744-756.

19 Forester JP, McWhorter DL, Cole MS. The relationship between premedical coursework in gross anatomy and histology and medical school performance in gross anatomy and histology. Clin Anat 2002: 15: 160-164.

20 Lou YP, Abrami PC, d'Apollonia S. Small group and individual learning with technology: a meta-analysis. Rev Educ Res 2001: 71: 449-521.

21 Herreid CF. Why isn't cooperative learning used to teach science? Bioscience 1998: 48: 553-559.

22 Cuseo J. The empirical case against large class size: adverse effects on the teaching, learning, and retention of first-year students. J Faculty Dev 2007: 21: 5-21.

23 Ditmyer MM, Dye J, Guirguis N, et al. Electronic vs. Traditional textbook use: dental students' perceptions and study habits. J Dent Educ 2012: 76: 728-738.

24 St Clair KL. A case against compulsory class attendance policies in higher education. Innov Higher Education 1999: 23: 171-180.

25 Kanter SL. To be there or not to be there: is attendance really the question? Acad Med 2012: 87: 679.
26 Thatcher A, Fridjhon P, Cockcroft K. The relationship between lecture attendance and academic performance in an undergraduate psychology class. S Afr J Psychol 2007: 37: 656-660.

27 Sade RM, Stroud MR. Medical student attendance at lectures: effect on medical school performance. J Med Educ 1982: 57: 191-192.

28 Gallagher JE, Dobrosielski-Vergona KA, Wingard RG, Williams TM. Web-based vs. Traditional classroom instruction in gerontology: a pilot study. J Dent Hyg 2005: 79: 7.

29 Walmsley AD, White DA, Eynon R, Somerfield L. The use of the internet within a dental school. Eur J Dent Educ 2003: 7: 27-33.

30 Rosenberg H, Kermalli J, Freeman E, Tenenbaum H, Locker D, Cohen H. Effectiveness of an electronic histology tutorial for firstyear dental students and improvement in "normalized" test scores. J Dent Educ 2006: 70: 1339-1345.

31 Salajan FD, Mount GJ. University of Toronto's dental school shows "new teeth": moving towards online instruction. J Dent Educ 2008: 72: 532-542.

32 Selvig D, Holaday LW, Purkiss J, Hortsch M. Correlating students educational background, study habits and resource usage with learning success in medical histology. Anat Sci Educ 2014. (in press). 